\title{
Restorative Justice with Female Offenders: The Neglected Role of Gender in Restorative Conferencing
}

\author{
Linnéa Österman ${ }^{1}$ and Isla Masson ${ }^{2}$ \\ Corresponding Author: \\ Linnéa Österman, University of Greenwich, Queen Mary Building, Old Royal Naval \\ College, London \\ SE10 9LS, UK.
}

Email: L.Osterman@greenwich.ac.uk

\begin{abstract}
This article presents findings from a new qualitative study into female offenders' experiences of restorative conferencing in England and Wales. It is argued that gendered factors of crime and victimization have a definite impact on the restorative conference process, particularly in the areas of complex and interacting needs, differently natured conference engagements, and risks around shame, mental health, and stereotypical ideals of female behavior. For women to reap the full benefits of restorative justice, it is argued that the particular needs and circumstances of female offenders must not only be acknowledged, but also incorporated into the field and mainstreamed into practice.
\end{abstract}

\section{Keywords}

female criminality, restorative justice, gender, female offenders, qualitative research, complex needs, women

\footnotetext{
${ }^{1}$ University of Greenwich, London, UK

${ }^{2}$ University of Leicester, Leicester, UK
} 


\section{Restorative Justice: A Growing Field With a "Woeful Lack of Evidence" on Women}

A recent political surge has led to a growing momentum to further develop and integrate restorative justice practices into the criminal justice system in England and Wales (Institute for Criminal Policy Research [ICPR], 2016; Miles, 2013). These expanding developments are founded on a significant, and increasing, evidence base that indicates numerous benefits of restorative justice, including positive victim effects (Strang, Sherman, Mayo-Wilson, Wood, \& Ariel, 2013), high levels of procedural justice, and a sense of citizen engagement (Daly, 1996, 2002) and the fostering of desistance related processes (Marder, 2013; Strang et al., 2013). The vast majority of this literature, however, is gender blind (Alder, 2000; Cook, 2006; Elis, 2005), and/or focuses exclusively on male samples. There is consequently a real lack of data in the area of gender and restorative justice (Strang, 2015). To date, research on women and restorative justice, commonly delivered by feminist authors, has almost exclusively focused on women as victims and the appropriateness of restorative practices in cases involving domestic and sexual violence. Authors in the field have accordingly called for a widening of the "feminist lens on restorative justice" (Daly, 2002, p. 1) and research that specifically explores female perpetrators' experiences of the practice (Daly \& Stubbs, 2006; Miles, 2013).

Restorative justice has different effects on different types of people (Strang, 2015), and conferences and outcomes are also affected by individuals' previous experiences, such as levels of disadvantage and trauma (Hayes \& Daly, 2004). In view of such evidence, the neglect of gender within offender perspectives is especially disconcerting as there is now a clear evidence base showing that women ${ }^{3}$ come into the criminal justice system with different backgrounds and experiences compared with their male counterparts. This includes pathways more commonly linked to sexual and physical victimization (Belknap \& Holsinger, 2006; Elis, 2005). Indeed, national as well as international research persistently demonstrates that women who

\footnotetext{
${ }^{3}$ For the purpose of this article, "women" and "females" are used as summary terms to refer to females of all ages.
} 
commit an offense are typically a victim first and an offender second (Rumgay, 2004; Verrecchia, 2009). Women coming into contact with the criminal justice system also present different needs compared with male offenders, and often deal with a range of concurrently occurring issues. These include living with the consequences of trauma and abuse (Covington, 2012), managing gendered aspects of child care (Gelsthorpe, Sharpe, \& Roberts, 2007), and being in unstable housing situations (Hannah-Moffat \& Innocente, 2013). Furthermore, it is known that mental health problems, as well as drug and alcohol misuse, have stronger links to female than male offending (Baird, 2003; Belknap \& Holsinger, 2006; Malloch, 2003). Women who offend also commonly report lower levels of self-esteem (DeHart, 2008). In addition, owing to traditional gender norms, female offenders typically experience higher levels of societal stigma compared with male offenders (Estrada \& Nilsson, 2012; McIvor, Murray, \& Jamiesen, 2004). It is this double transgression of both legal and social norms that has led some feminist scholars to position female offenders as "doubly deviant, doubly damned" (Heidensohn, 1996; Lloyd, 1995).

In view of this knowledge, recent years have witnessed an increasing recognition that the complexity of women's circumstances, experiences, and vulnerabilities need to be taken into account in order for the criminal justice system to effectively deal with their offending. In the United Kingdom, the Corston Report (Corston, 2007) marked a milestone in this area, arguing that women for too long have been marginalized in a system largely designed by and for men. Gender-responsive criminal justice approaches were accordingly called for. Although implementation has overall been slow, with the change agenda significantly diluted with the shift to a Conservative government in 2010 (Corcoran, 2010-2011), the Corston legacy is still strongly felt in the field. There is now a consensus among organizations and advocates working on the frontline of criminal justice in England and Wales that "a gender-specific approach to reduce reoffending is absolutely necessary if we are to address the needs of female offenders" (Clink, 2014, p. 19). National legislation is also reflective of these developments. For example, Section 10 of the 2014 Offender Rehabilitation Act contains gender-specific arrangements for female offenders, which ensures that the 
new supervision period framework complies with section 149(1) of the 2010 Equality Act $^{4}$ and meets the "particular needs of female offenders."

While these developments overall mark progress in the area of gender and justice, the currently expanding field of restorative justice has remained firmly outside of these advancements. There is a consequently a "woeful lack of evidence" regarding female offenders' interactions with, and experiences of, restorative justice conferencing (Miles, 2013, p. 8). The few gendered analyses that exist are largely of a theoretical nature, often focusing on the potential gendered benefits and risks. For example, some authors propose that restorative justice may be more beneficial for female offenders, as the process focuses on strengthening informal relationships (Elis, 2005), allows for a deeper assessment of personal circumstances, can give women and girls "a voice" (Verrecchia, 2009, p. 86), and is empowering (Alder, 2000). Others argue that restorative justice falls more in line with a female "ethics of care" (Failinger, 2005, p. 487). However, the idea that a female "ethics of care" links with a different form of justice is disputed. Daly and Stubbs (2007) argue that this assumption is misleading and empirically inaccurate. It moreover fundamentally neglects the more complex and nuanced scholarly work on morality and ethics that has followed since Gilligan's (1982) original writings on care and female/male voices (Daly \& Stubbs, 2007), such as Tyler's (2006) work on restorative and procedural justice and shared moral values. That said, Daly (2002) did find some gendered emotional effects of the restorative justice experience, with, for example, the victim's story having a more lasting emotional impact on offending girls compared with offending boys. As restorative justice has been identified to be a particularly useful intervention for improving a person's sense of self-worth (Marder, 2013), participation may also have positive effects on female offenders' mental health.

In contrast to these suggested benefits, the literature also highlights a number of gendered risks. A primary aspect of this is the risk, if not delivered appropriately, of

\footnotetext{
${ }^{4}$ Section 149(1) of the 2010 Equality Act requires that "a public authority must, in the exercise of its functions, have due regard to the need to eliminate discrimination, harassment, victimisation" based on gender. There is no specific inclusion of restorative justice either in this, or in the 2014 Offender Rehabilitation Act.
} 
exacerbating women's existing mental health problems (Miles, 2013). Aside from such preexisting vulnerabilities, female offenders have been found to generally internalize their coping mechanisms to a greater extent than male offenders (Holsinger, 2000). For example, it is known that women and girls who offend often struggle with particular levels of guilt, shame, and stigma, linked to the breaching of traditional gender ideals of being a respectable woman, a good mother, and a responsible citizen (Dodge \& Pogrebin, 2001). Indeed, the "good mother" ideology, suggested to permeate contemporary cultures, has been found to be especially closely linked to women's experiences of guilt and shame (Sutherland, 2010). This is an experience that is particularly accentuated in criminal justice contexts (Masson, forthcoming). In turn, these internalized emotions can negatively affect self-worth and identity. For some women, especially those with preexisting vulnerabilities, this is associated with heightened risks of self-destructive behavior (Alder, 2000). With the psychological implications of untreated female mental health problems and trauma, such as selfharm and substance misuse, representing major humanitarian as well as managerial problems in modern criminal justice (Rumgay, 2004), these concerns around risk are well-founded.

Moreover, a major criticism of restorative justice is its lack of recognition of the context in which offending and victimization take place (Daly, 2008), including the victimization-criminalization continuum (Balfour, 2008). Restorative justice conferences are inherently binary events, with a firmly defined victim and offender. Alder (2000) raises critical questions about this and the potential impact it may have on females in terms of judgment and self-portrayal. In addition, there are also risks associated with power imbalances and reinforcements of stereotypical female behavior. Restorative justice has received criticism for its potential to reproduce race, class, and gender relations, as well as for neglecting complex social and economic conditions and circumstances (Balfour, 2008). The inclusion of community members in restorative justice events means that community norms and values are often incorporated into the process (Rodriguez, 2005). Although this is commonly situated as a positive aspect of restorative justice, it is essential, as noted by Gaarder and Presser (2006), to ensure this incorporation of community norms does not 
inadvertently lead to an exacerbation of existing social injustices. Building on these combined bodies of literature regarding what is known about women who are involved in the criminal justice system, the evidenced value of gender-specific approaches in criminal justice practice, and feminist theorizing around gender and restorative justice, this article begins to address a major gap in knowledge in the restorative field: critically exploring the neglected role of gender in restorative justice conferences with female offenders.

\section{The Study: “Making Restorative Justice Work for Women Who Have Offended"}

This article draws on a selection of data collected for the research project "Making restorative justice work for women who have offended," a 7-month exploratory qualitative study funded by Barrow Cadbury Trust and delivered with the support of the Restorative Justice Council. ${ }^{5}$ Semistructured interview data were first gathered with practitioners who had experience of facilitating restorative justice conferences with convicted women. Drawing on the Restorative Justice Council's existing network, a total of 10 restorative justice practitioners were recruited, through a purposive sampling method, from a number of criminal justice sectors, namely, police, probation, youth justice, and community settings. ${ }^{6}$ Participants were sought across the country and no priority was given based on geographical proximity. The key criterion for inclusion was that practitioners had delivered restorative justice conferences with female as well as male offenders, which would allow the sample to make tentative comparisons between the genders. Practitioner interviews lasted roughly an hour, and both frontline and managerial position holders were interviewed within each of the sectors.

It should be noted that restorative justice programs in England and Wales are not standardized, and restorative conferences can take place at any stage of the criminal justice process. In a recent mapping exercise, 298 organizations across England and

\footnotetext{
5 The study ran from September 2015 to March 2016 and covered England and Wales.

${ }^{6}$ These are identified in the data presentation as POL, PROB, YOS, and COMM, respectively.
} 
Wales reported offering restorative justice provisions, ranging from voluntary sector organizations, prisons, youth offending teams, and local authorities to police forces and restorative justice hubs at police and crime commissioners' offices (ICPR, 2016). Types of funding structures and staffing arrangements vary widely across these organizations, with no uniform approach or model being operated.7 The provision can furthermore either be a part of a sentencing disposal or be postconviction (ICPR, 2016), though the former is predominantly relevant for youth. Reflecting this vast diversity in provision across England and Wales (CPS, 2016), no specific restorative justice models were targeted or selected for the recruitment process, and while some practitioners were "lay people," others were criminal justice practitioners. However, all of the interviewees had extensive experience of delivering restorative justice in their fields; supporting both female and male offenders throughout their entire restorative experience, from the preparation stage to postconference.

Second, grounded in a feminist methodological interview framework (Bloom, 1998; Maynard, 1994; Oakley, 1981), data were also collected with women who had firsthand experience of going through a restorative justice conference from a perpetrator perspective. As is anticipated when researching hard-to-reach populations, the recruitment of women with firsthand experiences of restorative conferencing proved challenging. Around 75 restorative justice premises and 60 women's centers ${ }^{8}$ across England and Wales were contacted for this recruitment process, and calls for participants were also advertised via a number of online restorative justice forums and meetings. This data collection process resulted in 11 interviews with women who had committed an offense and been through a restorative justice conference. ${ }^{9}$ Similarly to the practitioner interviews, no specific restorative

\footnotetext{
${ }^{7}$ For further detail on the type of restorative justice provision that are available at different stages of the criminal justice system in England and Wales, please see the ICPR's (2016) mapping exercise.

${ }^{8}$ One of the key recommendations from the 2007 Corston Report was that women's centers, which are specialist community "one-stop-shops" that provide a safe space and services for women with particular vulnerabilities in the criminal justice system, be developed and expanded in England and Wales. The Home Office does not centrally manage, or fund, these centers and therefore each center differs in whether it works alongside or within criminal justice settings. Their level of engagement in restorative justice provision is also geographically very varied.

${ }^{9}$ An additional three interviews were conducted with women with recent involvement in criminal justice, but who had not had the opportunity to engage in restorative justice. For the purpose of this article, these interviews are not included in the data presentation.
} 
model was targeted in the recruitment process, and the women's conferences differed with regard to whether they were part of a criminal justice process or not. Each interview lasted roughly half an hour, none of the women knew each other, and they were geographically spread out across different parts of England.

The female participant sample ranged in age between 15 and 60 years, and was diverse in terms of both offending histories and offense types. The time that had elapsed between offense and conference was also diverse and ranged from 2 weeks to 11 years, reflecting the fact that restorative justice in England and Wales can occur at any stage of the criminal justice process (CPS, 2016), as well as not being attached to sentencing or criminal justice procedures at all. The sample is not representative, but it reflects a range of female offenders' experiences of restorative justice practice in England and Wales. The majority of the cases related to various forms of theft and/or fraud, though there were two cases that would be classified as more serious in nature $-\mathrm{a}$ false allegation of rape and a murder. When the data collection stage was fully completed, the qualitative data were conceptually categorized and then analyzed using a semistructured thematic approach.

In support of the importance of independent research explorations of female offender experiences (Leverentz, 2014), this qualitative study was specifically designed to add a distinctive female perspective to the existing male dominated restorative justice literature. Accordingly, no comparison group was used. However, as noted, the practitioners included in the study were purposively sampled due to their experience with both male and female offender conferences. It was deemed that the combination of these data would enable a useful qualitative perspective of female offenders' experiences of restorative conferences. Future scholarly work that wish to build upon this research should aim to include a control group to make further comparisons between the experiences of both genders. Recognizing the usual limitations of any small-scale qualitative study (Mason, 2002), the findings should be viewed as exploratory, and do not lend themselves to empirical generalizations. Likewise, there are limitations in terms of quantification of the data. As identified by Pope, Ziebland, and Mays (2000), “qualitative sampling strategies do not aim to 
identify a statistically representative set of respondents, so expressing results in relative frequencies may be misleading" (p. 114). With this in mind, the authors have been mindful of avoiding quantifications of the small data set, although nonnumerical indicators, such as "most" and "many," are used to give the reader a rough sense of commonality within the sample. ${ }^{10}$

Recognizing these limitations, as the first study to date exploring the firsthand experiences of restorative justice conferences by women who have committed an offense, the findings make a significant contribution to the hitherto empirically neglected area of gender and restorative conferencing. Beyond feeding into the growing global evidence base on women and criminal justice practices, the findings also offer some important pointers for the embryonic debate of what gender-aware practices in restorative justice may, or in fact should, look like. ${ }^{11}$

\section{The Impact of Complexity on Restorative Justice Processes When Working With Women}

Adding support to existing international evidence on women and offending (Barberet, 2014; Corston, 2007; Estrada \& Nilsson, 2012; Gelsthorpe et al., 2007), the vast majority of the women's lawbreaking in this study took place in the context of complex needs and circumstances. Poor mental health was a dominant theme in this area, with the majority of the women reporting various forms of mental health problems at the time of the offense. For most, this was related to factors around coercive and violent relationships, living with the consequences of trauma, challenging child care and custody concerns, being in volatile housing situations, struggles with alcohol and substance abuse, poor physical health, and financial hardship.

A central element of restorative justice is that the offender accepts responsibility for his or her actions (Tyler, 2006). A genuine acknowledgment of this responsibility, along with the offer of restitution, is deemed to be a core factor for a successful

\footnotetext{
10 "Most" signifies a large majority and "many" a small majority of the sample, while "some" represents a large minority and "a few" a small minority.

${ }^{11}$ Article entitled "Working With Female Offenders in Restorative Justice Frameworks: Effective and Ethical Practice" focuses more exclusively on practitioner elements for the successful delivery of restorative justice with women.
} 
restorative intervention and effective victim recovery (London, 2011). Although there is an evidenced link between offending behavior and exposure to trauma, particularly for women (Moloney, van den Bergh, \& Moller, 2009), previous research has criticized the assumption that female offenders attempt to gain advantage and minimize responsibility for their actions through victimization narratives (Rumgay, 2004). Giving support to this argument, the findings in this study showed that complex circumstances and needs, such as previous victimization, trauma, or mental health problems, did not imply a subjective removal of culpability on behalf of the lawbreaking female. In fact, most of the women were keen to emphasize the opposite, stressing how the context of their offending was not an excuse for their offending behavior. This was, for example, illustrated by "Amelia":

I did say what had happened, so I talked about the rape, I said it was nonconsensual when I got pregnant, and that I had postnatal depression . . . But that was no excuse for what I did though ... And they said they forgave me, but I still haven't to this day to be honest with you, I still beat myself up about it. (Amelia)

The data also found support for the highlighted critique of a lack of sufficient recognition of the context in which offending and victimization take place (Daly, 2008). Both data sets showed marked differences in the space that was given to the offending context and case complexity in different restorative conference settings. While most of the women interviewed were given the chance to share the background of their offending during the conference in a safe and supported manner, a number of the women did not feel they were given that opportunity. It is noteworthy that conferences in which the women did not feel able and/or supported to share contextual and complex factors surrounding their offending were subjectively experienced, by the women themselves, as less meaningful. ${ }^{12}$ Interestingly, overall it was more common for those practitioners who were working in a statutory setting 13

\footnotetext{
${ }^{12}$ In this context, "meaningful" signifies an experience that had impact on the woman's subjective conceptualization of her offending behavior, and/or other aspects of her life.

${ }^{13}$ In the United Kingdom, context "statutory" refers to services that are funded and delivered by the state.
} 
to acknowledge a higher awareness of the importance of allowing space for the women to share contextual and complex factors surrounding their offending.

These findings fall in line with problems identified in the broader nongendered body of restorative justice literature, which show major definitional issues across the field, with, for example, extensive variability in meanings and practices having been identified (Daly, 2016; Daly \& Stubbs, 2006; Miles, 2013; Wood \& Suzuki, 2016). The present study provides further evidence in this area, demonstrating stark inconsistencies in the field in terms of how practitioners view their role, and relatedly, how much attention is given to contextual and complex factors in a case. This difference also extends to the understanding and exploration of gendered factors, and the impact that this may have on the process. This variability is exemplified in the following conflicting practitioner quotes:

I think I am always mindful of, with women, because I think women are so harshly treated by the criminal justice system anyway ... So before we get to conference, I would be different with women possibly than I would, I would be more mindful of how they have come to be in a position where they have committed that crime. (PR10: PROB)

Why people got to where they got to is not my job as a restorative justice facilitator ... My job is to look at whether they have victim empathy, what the crime was about, whether they take responsibility for the crime, whether they show remorse for the crime, whether they want to make amends for the crime. My job is not about exploring what got them to that point. (PR 5:

COMM)

The idea that restorative justice for women may be especially beneficial as it allows for a deeper assessment of personal circumstances and can give women "a voice" (Verrecchia, 2009, p. 86), seems to be reliant on which provisional setting the conference takes place within and the standard of quality of the facilitation. As highlighted in one of the few previous studies into women offenders and restorative justice (Miles, 2013), it must be critically questioned whether restorative justice can be effectively delivered with females when there is such a lack of consistency in recognition and approach to gendered factors of crime and victimization across the restorative landscape. The findings in this study clearly suggest that women who wish to share background factors to contextualize their offending should be offered appropriate support and encouragement to do so. This may go some way toward 
creating a more gender-aware restorative justice practice that not only gives more adequate attention to the victimization-offending continuum, but that is also likely to be more meaningful and empowering for the women taking part.

\section{Preparation and Flexibility}

Heightened complexity in female cases was evident in both the female offender and practitioner interviews, and was found to influence the restorative justice process in a variety of ways. First, it was commonly found that there were a number of issues that needed to be dealt with before commencing a conference, reflecting the chaotic circumstances women involved in criminal justice often are living in. In turn, these issues can make it especially demanding to get conferences off the ground, as noted by one practitioner, working in a probation setting:

I think the challenge is with women who've got complex needs, sometimes, some women, is that it's not a priority because they are living such challenging lives. So that is a distant thing which they, they need to focus on what's happening. So I think, for some of the women, within the chaos that they live every now and again they go: "Actually I could go and say sorry about that." So there is an awareness of the remorse, but actually they've got so many other things that they can't stick with that because something else comes in and trumps that particular desire. (PR 4: PROB)

For the conference to be effective, the participating individuals must be ready. For many women, that may mean dealing with more acute factors before they can consider entering a restorative conference process. There were examples in the data when a conference was pushed through before other, arguably more pressing factors, such as homelessness and alcohol dependency, had been given appropriate time and consideration. The conference experience was in consequence not only hugely challenging to the woman, but also in many ways ineffective. For a few women, this resulted in severe anxiety and panic attacks in and around the event.

A key consequence of the heightened levels of complexity in female cases was the need for a more flexible approach, which was identified as a particularly important part of effective restorative justice delivery with women. As highlighted by one practitioner, speaking from a police perspective, 
I think we have to be more flexible [with female cases] . . It's that whole preparation that goes into it, you know? You really have to understand the complexity of the females' lives, which will be more ... than the males, but you have to, before you go into that conference. It might take more time, more preparation, more flexibility and more understanding. There's issues that might never come out, issues that you can't research and prepare for beforehand, that's the reality, it's just more complex. (PR 3: POL)

It is known from the wider body of literature on restorative justice that preparation is essential for a successful conference (Shapland et al., 2007). This is likely to be a timeconsuming process (Sherman, Strang, Mayo-Wilson, Woods, \& Ariel, 2015), which includes both emotional and practical components that can vary significantly from case to case (Miller, 2011). Supporting the importance of suitable preparation, the data suggested that for a gender-aware practice this must include allowing for flexibility in case working, as well as an exploration of the presence of other, often complex and acute, issues. If this complexity is not considered, it may impede the beneficial aspects of the process to the women participating.

\section{Prior Relationships}

An additional factor that was suggested by the practitioners to often create further complexity in female cases was the presence of more complicated relationships with victims. Previous studies have shown that females are more likely to come into a restorative justice conference with cases linked to preexisting relationships (Daly, 2002; Miles, 2013). This research found further evidence for this argument. In turn, these prior relationships typically made the case more complex to process, as highlighted by one practitioner working in the youth justice system:

What girls probably find more difficult is getting past that prior relationship. You know, whether they feel they can physically step into a room and face the person that they were once perhaps friends with. So I think that's probably the difference. It is definitely more complex. (PR 1: YOS)

Conferences involving known parties often contain more contested facts, have "blurred lines" between victim and offender, and involve less apologetic behavior; all of which have been found to be negatively associated with positive conference outcomes, including reoffending rates (Daly, 2008; Hayes \& Daly, 2004). The higher 
prevalence of cases involving known parties among females may therefore have gendered consequences in terms of reduced positive outcomes.

In addition, the findings indicated that prior relationships did not only make a case more complex due to contested facts, but also due to the emotional weight of the participant experience. For example, Magdalena undertook restorative justice with her brother. The conference was the first time they had met since she was sentenced, and due to the sensitivity of the relationships concerned, it was a highly complex and time-consuming process. As described by Magdalena:

The victim was my mum, and he's my brother ... I'm the only family he's got ... so when my mum gone and I'd got brought to prison, he'd lost everything and he'd lost everybody ... I was so scared, I just kept putting it off . . . I didn't want to do it, or I did want to do it but I was just so scared of facing him, and so ashamed and ... . with the guilt and everything, I was just so so scared of meeting him. (Magdalena)

Recognizing this additional level of emotional complexity in cases involving known parties, there was a parallel suggestion in the data that if these more intricate cases are dealt with appropriately, the repairing of those relationships may actually have particular, and wide-ranging, beneficial consequences. As Practitioner 1 suggested:

With the kind of prior relationships ... for females it absolutely repairs those relationships, because they were, there was a link before. So for instance in the $X$ case, it happened at school, they were in the same year, they were both leading up to their GCSEs, so it was really important for both of them, and yet it was this incident that had made things really kind of awkward. And actually ... by the end of [the conference process] the awkwardness had gone. The offender in particular, her attendance at school improved significantly . . . So in that respect it was just huge. (PR 1: YOS)

This wider impact, especially in terms of repairing relationships, was also echoed in the female offender data. Revisiting Magdalena's case, she expressed this when she spoke about how she saw her relationship with her brother developing following the conference:

I think when I am starting to go out [from prison] I think that's when we'll get together, and we've had that initial meeting and we've had that initial contact ... And even though he doesn't understand what I did and why I did it, he still cares about me, like I care about him. I think it's gonna make things a lot easier, the path a lot easier now, you know, we'll be able to talk more and, you know, go through a lot more things in depth ... I've got my brother back. (Magdalena) 
There is a suggestion here that the restorative justice process can pave the way for prior relationships, when appropriate, ${ }^{14}$ to not only be repaired but also be developed further. In turn, this may positively affect the woman's life, and falls in line with the suggested gendered benefits identified in the literature, especially around the strengthening of informal networks (Elis, 2005). That said, the presence of prior relationships undoubtedly makes the conference proceedings more complex, and while each case will be different, for the full benefits to be reaped the process must offer enough time for the individuals involved to consider those relationships in a meaningful way.

\section{Gender and the Conference Meeting}

Beyond the preparation stage, this study found evidence that indicated that gender is a relevant factor also in the restorative conference meeting. This was specifically detected in the themes "engagement and interaction," "emotional aspects of the process," and the role of "informal and formal support."

\section{Engagement and Interaction}

The findings lent support to the notion that women engage in the restorative justice conference process in somewhat different ways to men, which, in turn, may be beneficial to the outcomes of the event. Although women may take longer to get to the conference stage, due to the noted issues around complexity, many practitioners felt that when women do take part it is typically more heartfelt. Some practitioners linked this to the idea that women may internalize more:

We [men] don't tend to internalize stuff as much ... It's done and dusted then, so it's kind of an easier thing to do. You know: "yeah I'm sorry," you move on. While actually, for a female offender it would probably be more heartfelt to be

\footnotetext{
${ }^{14}$ It must be recognized, as highlighted in the literature around female domestic victimization and restorative justice (Stubbs, 2002), that there may be cases where reparation and an apology is neither suitable nor safe for the woman, such as when the offense is in response to ongoing threats and violence.
} 
involved in that process, but they're not ready and they're not in that place to be, because they've got all these other things to deal with. (PR 7: POL)

Connected to this more heartfelt involvement, the data also suggested a prevailing practitioner experience of women as better communicators, which commonly had a positive impact on the running of the conference. For example:

With a woman offender, we just sat back and they spoke, you didn't have to read off the questions off the script . . Less prompting, 'cos they'll just start and then they'll carry on ... With a man you'd, they'd say a sentence and then they'd look at you for guidance, and you'd go "ok so what did you feel about this?" And then they'd answer that and then they'd look at you again. Yeah so there was a lot of scripted moments with men, with women it was more heartfelt. (PR 8: COMM)

This same practitioner went on to explain how, in her view, the way that women and men engage differently in the process may also affect the long-term beneficial impact of the conference:

Women don't forget. I think men, in my experience, they can forget about emotion, they can cry, we've had bogies hanging down and sobbing and pleading for forgiveness, and five minutes later they're talking about the football results. Whereas women are distressed for hours, you know, long time after, and they don't forget. So I think that's where it can be powerful. (PR 8: COMM)

While it is debatable whether these factors are linked to a so-called "female ethics of care" (Failinger, 2005, p. 487), the findings from this study do indicate that females may engage in the process in a different way to men, including via a more heartfelt and open-dialogic conference involvement. Due to these factors, in combination with more invested involvement and personal relationships potentially being repaired, these positive outcomes for women may also be more long term.

\section{Emotion in the Conference Setting}

The limited studies that exist suggest that gender may interact with the emotional aspects of restorative justice conferencing, including more physical displays of emotion (Daly, 2002; Miles, 2013). Although this study can say little about the comparative firsthand experience of male and female restorative justice participants, 
it gives support to a general high level of female emotional involvement in the conferences. For the vast majority of the women interviewed, the conference was subjectively experienced as highly emotional. However, although there is a common stereotype that women are more emotional than men (Kelly \& Hutson-Comeaux, 1999), some of the findings suggest that the presence of emotion in the restorative justice process needs more nuanced and critical exploration. Rather than being simplistically linked to gender, there may be other factors that influence the level of emotion in the conference. Specifically, a clear association was found in the data between the nature of the offense and the level of emotional impact. Several of the female participants expressed the view that restorative justice may be more impactful in cases involving prior or personal relationships, illustrated in comments, such as:

With restorative justice I kind of think, for me it felt like it's more of a personal thing. (Laila)

If it would have been a stranger then it might not been as much impact. (Magdalena)

Given the previous noted findings regarding a higher prevalence of prior relationships between victim and offender in female cases, the suggestion that a prior relationship may make the conference more emotional and impactful could have gendered significance.

In contrast to the female interviews, the practitioner data can provide an insight into the comparable role of emotion in male and female conference settings. Offering a challenge to a simplistic binary gender distinction in the display of emotions, the practitioner data overall suggested a more complex association between gender and emotion, exemplified in the following quote:

If anything it's been more emotional dealing with men . . . I think because women operate at a more emotional level generally, that restorative justice isn't anything particularly more emotional than they're used to ... From early on women are encouraged to be emotional, so it's not . . . a negative thing for [them] to be emotional, whereas, you know, from early on little boys are discouraged from showing emotions ... So actually when it comes to a restorative justice conference, men are confronted with a situation where they can't help themselves ... I think for men it is, it is quite often the most emotional thing they've done for a long time, and it's ok to be emotional in that situation. (PR 10: PROB) 
There is thus a suggestion that women's socialization processes mean that, generally, they are more open emotional actors, while traditional masculine ideals teach men to be emotionally restrained (Broady, 2000). With a high value being placed on emotional interactions and open communication in restorative conferences, the process may provide a more unique emotional space for men, signifying a more marked disruption from heterosexual male gender norms. These findings are in line with research that challenges the typical gender-emotion stereotype and instead suggest that our understanding of gender and the emotional and the unemotional is contextdependent (Kelly \& Hutson-Comeaux, 1999).

That said, due to gendered conditioning and traditional social norms, it may be that women are accustomed to a more open emotional gender identity. As a result, they may be more experienced with the use of emotions. Indeed, the data did suggest a perception on behalf of practitioners that female offenders were typically more in tune with their emotions compared to men. There were clear links between this finding and a perception of more readily available forms of empathy in female cases, which again lends support to the notion of particular gendered benefits of the process (Elis, 2005; Failinger, 2005). In turn, these themes also overlapped with the previously highlighted findings regarding female conferences often being more "heartfelt" and more dialogic. Overall, these factors may jointly interact to make the restorative justice process particularly beneficial to female participants.

\section{Informal and Formal Support}

One of the largest studies into restorative justice conferences to date, a study of youth conferences in Australia led by Kathleen Daly (1996), detected clear evidence that conferences are highly gendered events. For example, it was found that while few offenders were female, the majority of supporters were. This is in line with the wider literature on women as providers of support and enablers of male desistance (Leverentz, 2006). In contrast, intimate relationships with men have been found to often act as a barrier to female desistance (Cobbina, 2010; Österman, 2008). This study found evidence for this gendered notion of support also in the restorative justice context. In fact, despite all of the women who participated in this study being offered 
the option to do so, hardly any brought any type of personal support with them into the conference, and none brought in a current partner. Instead, most of the women felt that the support provided by a professional worker ${ }^{15}$ was adequate, as stated by Laila:

I did have the option to take somebody if I wanted and I did think about it, and then in the end, because I was comfortable with [probation officer] and [restorative justice worker], I didn't feel I needed to . . . I felt I was supported as much as I needed to be. (Laila)

A positive working relationship with a professional of this type commonly meant that the women did not feel they required additional, personal, conference support. The relationship building aspect of this theme is significant, and echoes the important, and often demanding, role of emotional labor undertaken by staff working with offender populations (Crawley, 2004). This also came through as a strong gendered factor, with a dominant view that relationship building plays a particularly important role for effective working with women. This was a theme that was expressed by practitioners working both with young and adult women, and is exemplified here by a practitioner coming from a probation perspective:

Very often what they got out of it was the relationship with the facilitator as much as the conference. It was such a supportive relationship, it was so nonjudgmental ... It was empowering; it helped her to believe she could do it. So I think the importance of the relationship is possibly more important to empower the women to believe they can do it, when they maybe have some self-doubts. (PR 4: PROB)

There are again beneficial gendered links here to the value of it being an empowering experience for the woman, facilitated through a supportive professional relationship. The data clearly suggested that when a positive and open working relationship was built, the women were more likely to have a positive experience of the restorative justice process as a whole.

There were, however, examples in the data where this type of positive working relationship did not happen, with negative outcomes for the female conference experience. There is an important gendered variable within this theme, with the gender of the restorative justice worker suggested to be pertinent. A prime example

\footnotetext{
${ }^{15}$ Professional in this context refers to a person working with the woman in some form of a professional capacity, rather than in a conference facilitating capacity; key examples being a probation officer, a prison chaplain, or a member of staff at a women's center.
} 
of this was found in the case of India, who did not feel understood by the male facilitator leading her case:

I think he prejudged me because he was like, when I told him all stuff that, it's not like I was looking for a get-out clause or something . . . but I wanted to make him aware that it's not just like, to get money for drugs or, obviously there were massive issues and stuff, you know . . . I think it would have been different if it were a woman, 'cos I think a woman working with a woman, doing restorative justice, they know where they're coming from. (India)

The data indicated a particular value in having a female restorative justice facilitator in female cases, to enable the woman to feel in a better position to share the context of her offending. This theme also overlaps with the noted findings on the positive aspect of feeling supported to share background factors and offending circumstances within the restorative justice process. As previously highlighted, many of the women had experiences of dealing with gendered issues, such as, for example, sexual victimization and child care issues, in and around their offending, and for some these were ongoing through the restorative justice process. It is suggested that experiences such as these may be more easily shared in a female-to-female relationship. This finding falls in line with current developments in criminal justice policy and practice in England and Wales, including gender-specific outputs in the Ministry of Justice's recent contracts that support women who have served short prison sentences. ${ }^{16}$

\section{Gendered Risks: Shame, Guilt, Vulnerability, and Stereotypes}

The focus thus far has predominantly fallen on the potential gendered benefits of restorative justice with women offenders; however, there are also a number of potential gendered risks identified in the literature. This study found new evidence for both the presence and the consequences of these risks in restorative justice practices. From practitioners' perspectives, shame and guilt, and associated potential

\footnotetext{
${ }^{16}$ Specifically, providers will need to give female offenders the option, where practicable, of (a) having a female supervisor/responsible officer, (b) attending meetings or appointments in a femaleonly environment, and (c) not being placed in a male-only environment for unpaid work or attendance requirements (Ministry of Justice, 2014)
} 
mental health risks, were identified as particularly concerning, exemplified in quotes such as:

It could make their self-esteem worse. It might be times where, if they're quite vulnerable, it could make them feel dreadful . . . There's a lot of self-harmers in Holloway ... It's a massive problem there. So there could be those issues, which is something that has to be looked at. (PR 8: COMM)

To further problematize the concerns regarding mental health, a major identified issue was a lack of consistency in adequate mental health assessments. Assessments were patchy at best and nonexistent at worst. One practitioner, working in a community setting, admitted the challenges of assessing for mental health, stating that it is not uncommonly omitted due to a lack of knowledge of how to do it. This raises serious concerns about ethics and responsibilities toward participants in terms of ensuring that the restorative justice process does not exacerbate preexisting vulnerabilities.

There were, however, parallel examples of positive effects on mental health from the conference experience. Many practitioners felt that restorative justice could provide an opportunity for complex and challenging emotions to be managed in a "less destructive" way:

Restorative justice might get them, help [women] ... manage the shame in a way that is not destructive ... It's such a respectful intervention, it could help them see that this is an incident that they can get closure on and that they can give the victim closure on, that might give them the impetus to, kind of, work on other interventions ... Restorative justice is not a program for changing your behavior . . . but it can create great impetus for having a different type of life. (PR 4: PROB)

There are two contrasting trajectories here then; on the one hand, if not managed properly, restorative justice may exacerbate mental health and other interlinking problems, while on the other hand, it may help convicted women better manage existing problems and provide impetus for new directions. The data in this study found evidence for both sides of these two trajectories. The majority of the cases, however, fell in the positive category.

In terms of the women's narratives, guilt and shame were particularly prominent themes when discussing mental well-being, often narratively conjoined with a subjective sense of responsibility and culpability. How the experience of guilt and 
shame affected the person and the process, however, varied. Positively, for many of the women interviewed, the most powerful outcome of the restorative experience was the alleviation or removal of guilt, as exemplified in quotes such as:

The conference made the guilt better, or I learnt how to deal with it a little better. (Keira)

For Keira, this removal of guilt was linked to acceptance, and the approval to put the offending label behind her:

He shook my hand, said thank you to me, and I was just in floods of tears, and he said: "I hope you gain from this what I've gained, and that you can move on with your life in a positive way," and that to me was just a huge turning point. (Keira)

However, for a minority of the women, it was not so straightforward, and despite their victim not expressing further anger or hatred, they continued to be negatively affected by guilt. For a small minority, the conference even subjectively made the situation worse, as exemplified by Laila:

I had already visited very deeply the whys, and why things have turned out the way they have done and stuff like that. So, you know, and I took my own actions very hard as well and I had a lot of guilt about it. So I think me personally, I don't think I really got anything out of it, only a bit more stress . . . I was still, and I suppose I am a little bit now still, feeling very guilty . . . I don't know why really ... I just walked away from it feeling drained. (Laila)

While recognizing that each case is different, an overarching important factor for the positive management of guilt and shame was the quality of restorative justice work that the woman was offered. Factors such as suitable preparation work, including adequate assessments around mental health, good organization of the event, and the provision of quality after-support, were key in this area (see Masson \& Österman, 2017).

\section{Stereotypes and Traditional Gender Norms}

Lending support to existing literature around gendered risks (Cook, 2006), this study found evidence for the existence of stereotypical norms in the field of restorative justice. Specifically, there was a gendered theme present in a minority of the data around negative stereotyping of women who offend. The presence of preconceived 
ideas about gender and behavior in community representation was, for example, identified by a practitioner working in a youth justice setting:

Well they [the criminal justice system] criminalize females more than, you know, because of this whole idea of: "you look like a nice-looking girl, why did you get involved? You shouldn't have done that!" . . . I have seen on the odd occasion, where it's ... "it's a girl and she's assaulted?" Where it's: "Oh he's assaulted." So you say, "No hang on, this is a young person," male or female, you shouldn't, you shouldn't differentiate, deal with them as who they are, not that preconceived idea that: "oh they're female and this is absolutely disgusting!" whereas if it would be a lad it would be alright. (PR 2: YOS)

This theme was not only present in the youth section of the data, but also with practitioners working within the adult criminal justice system. This included a recognition that the way women who have committed an offense are judged is likely to be different from their male counterparts. In turn, this may have consequences for their overall experience of justice, including that of restorative processes:

Do we deal differently with ... female offenders? I think probably yes, you know, because society does . . Because we do things, like: "How can you do that when you got three kids and you're a mother?" and you know, we're not saying that about dads who do that. (PR 3: POL)

These findings not only give support to the continued impact of traditional gender norms on women's experiences of criminal justice, but that the notion of "doubly deviant, doubly damned" (Heidensohn, 1996; Lloyd, 1995) may also be relevant for restorative justice practices. Through the application of gendered scripts, there is a risk that particular norms and ideals about suitable female behavior may be reinforced in restorative justice processes (Cook, 2006). This is an area that requires more research, and one that would particularly benefit from observational data gathering. Furthermore, as is increasingly recognized in the restorative justice literature that deals with women, domestic violence, and restorative justice (Stubbs, 2002), to include an intersectional framework, which explores multiple layers of disadvantage in overlapping identities in such future scholarship, would further strengthen its merits. 


\section{Restorative Justice: An Opportunity for Wider Female Engagement and Gender-Responsive Support?}

Due to the high level of complexity in most female offenders' lives, restorative justice is likely to be one of many mechanisms that can offer positive change. The role of partnership working between different agencies and signposting to appropriate support providers is therefore essential. However, this area was identified in the study as significantly lacking, which may, due to the higher prevalence of complex needs, be especially pertinent to the female experience. As noted by one practitioner:

It is far more complex than the simple female offender label, and therefore it does need those extra considerations around the person. What led you to be where you are today, and tracking that back. That's gonna take an awful lot of time and it's gonna take some specialist resources as well, way beyond the general skills and abilities of a restorative justice practitioner. (PR 7: POL)

It is known that women who engage in offending often lead very isolated lives (Rumgay, 2004). Involvement in restorative justice could therefore be seen as an opportunity for wider engagement, over and beyond the conference itself, with organizations supporting positive change. As postulated by Practitioner 7:

What I think it could do is that it could provide, a restorative justice practitioner could provide a catalyst for a referral ... That's what we need to do ... go back and revisit it once whatever it is that's going on has been dealt with. (PR 7: POL)

Gender-specific services, such as women's centers, are more likely to offer service provision that is gender-responsive, and have the right expertise to identify and effectively treat complex female needs (Scott \& McManus, 2016). Situated in a safe, familiar, and supportive context, women, and those supporting them toward change, are more likely to make informed decisions about suitable processes. Not all women who offend are in need of professional support to move their lives in a positive direction, yet, many are. Only a small minority of the women interviewed for this study had contact with women's centers. The few who did, however, attached huge beneficial value to that connection. As highlighted by Bethany, who came in contact with the local women's center through her restorative justice involvement:

'Cos some of them like, like I said I have, going through depression and that, and it's not just a case of: "She's done this, she's done that," she might have 
other problems and I think the women's center might be able to help them with that as well. Not just, you know, the criminal thing that they've done, but looking at her in other ways as well ... It has just been nice to come here ... You're not judged at all either, for what you've done, that was nice. (Bethany)

Though recognizing the value of this interaction, issues remain in women getting a chance to access such centers. As pointed out by Keira:

I do think more stuff needs setting up for women especially, it's not enough, I mean I'd never heard about the women center until I offended ... They do so much good work there, but not enough people know about it, and that's what needs to change. It's not publicized enough; do you know what I mean? So the women that do need it don't know it's there until it's perhaps too late. (Keira)

As suggested by Keira's experience, access to gender-specific support is not always obtainable or clearly signposted. Provision is based on the availability of local resources, and it is noteworthy that recent years have seen increasing financial insecurity posing severe threats to community service provision in England and Wales (Clinks, 2014; Scott \& McManus, 2016). ${ }^{17}$ Echoing previous suggestions in the field (Miles, 2013), the findings in this study indicate that there is huge potential value in investing in the development of links between restorative justice facilities and women's centers. This is likely to open up effective signposting avenues, which increases the opportunities for restorative justice to be introduced, and for the female's ability and willingness to participate to be assessed, in a working context where there is familiarity and expert knowledge of the specific issues at hand. It is suggested that if done effectively, these links have the potential to enable more women who have committed an offense to access and have a positive experience of restorative justice.

\section{Summary and Conclusion}

Despite a recent increase in interest and scope in restorative justice, very little to date is known about female offenders' experiences of restorative conferencing. It is known that women's pathways into crime differ significantly from their male counterparts,

\footnotetext{
${ }^{17}$ This was also directly felt in the present study, as around a fifth of the women centers contacted for participant recruitment had either closed down due to having lost all of their funding or had lost some funding and were therefore no longer working with women involved in the criminal justice system.
} 
as do their experiences in the criminal justice system and the treatment and judgment that they face in wider society. Positively, there has been a growing recognition of these differences in criminal justice policy and practice in recent years, including an acknowledgment that applying gender-specific approaches are likely to be more effective when working with women. Restorative justice has, however, thus far remained firmly outside of these developments. With the aim to incorporate the gender equality framework (Equality Act, 2010) into all factions of the criminal justice system, there is a pressing need for an improved understanding of women's specific experiences of restorative justice. This article begins to address this previously unexplored criminological area. While bearing in mind the exploratory nature of this qualitative study, the data have tentatively demonstrated that high levels of complexity, so common in the lives of women who are involved with criminal justice, affect the restorative justice process in a number of ways. This includes the need to deal with multiple and concurrent issues in the women's lives, and the higher presence of preexisting relationships between offender and victim. The gendered context of complexity was, however, not something that all practitioners recognized, nor were background factors an area that all practitioners viewed as part of their working role. For restorative justice to not fall behind wider criminal justice developments, a gender-aware practice must include fostering consistency in working approaches across the restorative justice field in these areas.

The findings show evidence of both potential gendered benefits as well as risks of restorative justice. Themes that came through strongly in terms of benefits included a more engaged and heartfelt female involvement, with higher levels of communication and readily available empathy. These factors lend some support to suggestions in the literature (Alder, 2000; Elis, 2005; Failinger, 2005; Verrecchia, 2009) that women may reap greater positive effects from restorative justice conferences compared to men. For a gender-aware practice, it is argued that practitioners should have an awareness of factors that may be especially valuable for fostering long-term positive outcomes in restorative justice cases with women. In contrast, also reinforcing theorizing in the field (Alder, 2000; Balfour, 2008; Cook, 2006; Miles, 2013), risks relating particularly to factors around shame, guilt, mental health, and stereotypical ideals surrounding 
appropriate female behavior were identified. A deterioration of mental health was identified as a particular gendered risk, with associated risks of self-harm. Seen through this lens, restorative justice shares many of the problems faced in wider criminal justice settings, with the legacy of female victimization experiences presenting a huge concern in contemporary penalty (Rumgay, 2004). These realities raise broader critical questions about harm, punishment, and inequalities; questions that stretch far beyond the specifics of restorative justice. However, recognizing these wider concerns, it is still worthwhile to improve practice on the micro level, ensuring that, at the very least, restorative justice does not add to preexisting vulnerabilities. The findings showed that negative experiences were quite specifically linked to a poor restorative justice service delivery, such as inadequate mental health assessments and poor organization of the event. While quality in practice is undoubtedly essential for all restorative justice cases, the makeup of the female offender population, with particular high levels of needs and vulnerabilities, mean that poor practice may indeed have particularly acute consequences for this group. If restorative justice is carried out in a mindful and high-quality manner, however, it can provide an opportunity for complex and challenging emotions to be managed in less destructive ways. Moreover, if suitable attention is given to contextualizing factors, restorative justice may also go some way to counter the problematic binary construction of victims and offenders (Burman, 2010) inherent in more traditional forms of criminal justice.

To conclude, restorative justice conferences offer no magic bullet for female offenders; however, if high-quality practice, including well-established links with other support agencies, is delivered, it can provide a valuable opportunity for a starting point toward positive change for women who offend. In order for this to happen, the particular needs and circumstances of women entangled in criminal justice must not only be acknowledged, but also incorporated into the field and mainstreamed into practice. 


\section{Declaration of Conflicting Interests}

The author(s) declared no potential conflicts of interest with respect to the research, authorship, and/or publication of this article.

\section{Funding}

The author(s) received no financial support for the research, authorship, and/or publication of this article.

\section{References}

Alder, C. (2000). Young women offenders and the challenge for restorative justice. In H. Strang \& J. Braithwaite (Eds.), Restorative justice: Philosophy to practice (1st ed., pp. 105-119). Abingdon: Ashgate.

Baird, V. (2003). Commission on women and the criminal justice system. Current Issues in Criminal Justice, 22, 30-31.

Balfour, G. (2008). Falling between the cracks of retributive and restorative justice: The victimization and punishment of aboriginal women. Feminist Criminology, 3, 101-120. Barberet, R. (2014). Women, crime and criminal justice: A global enquiry. New York, NY: Routledge.

Belknap, J., \& Holsinger, K. (2006). The gendered nature of risk factors for delinquency. Feminist Criminology, 1, 48-71.

Bloom, L. R. (1998). Under the sign of hope: Feminist methodology and narrative interpretation. Albany: State University of New York Press.

Broady, L. (2000). The socialization of gender differences in emotional expression: Display rules, infant temperament, and differentiation. In A. Fischer (Ed.), Gender and emotion: Social 24 Feminist Criminology 13(1) psychological perspectives (1st ed., pp. 24-47). Cambridge, UK: Cambridge University Press.

Burman, M. (2010). The ability of criminal law to produce gender equality: Judicial discourses in the Swedish criminal legal system. Violence Against Women, 16, 173-188. Clinks. (2014). Who cares? Where next for women offender services? London, England: Author. Cobbina, J. E. (2010). Reintegration success and failure: Factors impacting reintegration among incarcerated and formerly incarcerated women. Journal of Offender Rehabilitation, 49, 210-232.

Cook, K. J. (2006). Doing difference and accountability in restorative justice conferences. Theoretical Criminology, 10, 107-124.

Corcoran, M. S. (2010-2011). Snakes and ladders: Women's imprisonment and official reform discourse under New Labour. Current Issues in Criminal Justice, 22, 233-252.

Corston, J. (2007). The Corston report: A review of women with particular vulnerabilities in the criminal justice system. London, England: Home Office.

Covington, S. S. (2012, January 10-12). Trauma matters: Creating services for women.

Paper presented at the Conferences on Women, Crime and Criminal Justice Conference, University of Cambridge, UK.

CPS. (2016). Restorative justice. Retrieved from http://www.cps.gov.uk/legal/p_to_r/restorative_justice/\#an02

Crawley, E. M. (2004). Emotion and performance: Prison officers and the presentation of self in prison. Punishment $\mathcal{E}$ Society, 6, 411-427.

Daly, K. (1996, November 20-23). Diversionary conferencing in Australia: A reply to the 
optimists and skeptics. Paper presented at the American Society of Criminology Annual Conference, Chicago Marriott Hotel, USA.

Daly, K. (2002, November 20-23). Widening the feminist lens on restorative justice. Paper presented at the American Society of Criminology Annual Conference, Chicago Palmer House, USA.

Daly, K. (2008). Girls, peer violence, and restorative justice. Australia $\mathcal{E}$ New Zealand Journal of Criminology, 41, 109-137.

Daly, K. (2016). What is restorative justice? Fresh answers to a vexed question. Victims $\mathcal{E}$ Offenders: An International Journal of Evidence-based Research, Policy, and Practice, 11, 1-21.

Daly, K., \& Stubbs, J. (2006). Feminist engagements with restorative justice. Theoretical Criminology, 10(9), 9-28.

Daly, K., \& Stubbs, J. (2007). Feminist theory, feminist and anti-racist politics, and restorative justice. In G. Johnstone \& D. W. Van Ness (Eds.), Handbook of restorative justice (1st ed., pp. 149-170). Devon, UK: Willan Publishing.

DeHart, D. (2008). Pathways to prison: Impact of victimization in the lives of incarcerated women. Violence Against Women, 14, 1362-1381.

Dodge, M., \& Pogrebin, M. (2001). Collateral costs of imprisonment for women:

Complications of reintegration. The Prison Journal, 81, 42-54.

Elis, L. (2005). Restorative justice programs, gender, and recidivism. Public Organization

Review, 5, 375-389.

Equality Act, c.15 U.K. (2010).

Estrada, F., \& Nilsson, A. (2012). Does it cost more to be a female offender? A life-course study of childhood circumstances, crime, drug abuse, and living conditions. Feminist Criminology, 7, 1-24.

Failinger, M. A. (2005-2006). Lessons unlearned: Women offenders, the ethics of care, and the promise of restorative justice. Fordham Urban Law Journal, 33, 487-526.

Gaarder, E., \& Presser, L. (2006). A feminist vision of justice? The problems and possibilities of restorative justice for girls and women. In D. Sullivan \& L. Tifft (Eds.), Handbook of restorative justice: A global perspective (1st ed., pp. 483-494). Abingdon, UK: Routledge. Gelsthorpe, L., Sharpe, G., \& Roberts, J. (2007). Provision for women offenders in the community (A Fawcett Society Research Report). London, England: Fawcett Society.

Gilligan, C. (1982). In a different voice. Harvard, MA: Harvard University Press.

Hannah-Moffat, K., \& Innocente, N. (2013). To thrive or simply survive: Parole and the postrelease needs of Canadian women exiting prison. In B. Carlton \& M. Segrave (Eds.), Women exiting prison: Critical essays on gender, post-release support and survival (1st ed., pp. 77-97). New York, NY: Routledge.

Hayes, H., \& Daly, K. (2004). Conferencing and reoffending in Queensland. Australia \& New Zealand Journal of Criminology, 37, 167-191.

Heidensohn, F. (1996). Women and crime (2nd ed.). London, England: Macmillan.

Holsinger, K. (2000). Feminist perspectives on female offending: Examining real girls' lives. Women and Criminal Justice, 12, 23-51.

Institute for Criminal Policy Research. (2016). Report of a mapping exercise of restorative justice provision in England and Wales for the Restorative Justice Council. London, England: Birkbeck, University of London.

Kelly, J. R., \& Hutson-Comeaux, S. L. (1999). Gender-emotion stereotypes are context specific.

Sex Roles, 40, 107-120.

Leverentz, A. M. (2006). The love of a good man? Romantic relationships as a source of support or hindrance for female ex-offenders. Journal of Research in Crime $\mathcal{E}$ Delinquency, $43,459-488$. 
Leverentz, A. M. (2014). The ex-prisoner's dilemma: How women negotiate competing narratives of re-entry and desistance. New York, NY: Rutgers University Press.

Lloyd, A. (1995). Doubly deviant, doubly damned: Society's treatment of violent women. London, England: Penguin Books.

London, R. (2011). Crime, punishment, and restorative justice: From the margins to the mainstream. London, England: FirstForumPress.

Malloch, M. S. (2003). Women of substance: Drug using women and criminal justice. Criminal Justice Matters, 53, 24-25.

Marder, I. (2013). Restorative justice for young adults: Factoring in maturity and facilitating desistance (A Barrow Cadbury Trust, T2A and Restorative Justice Council Report). London, England: Restorative Justice Council.

Mason, J. (2002). Qualitative researching (2nd ed.). London, England: Sage.

Masson, I. (forthcoming). Incarcerating motherhood: The enduring harms of first short periods of imprisonment on mothers. Oxford, UK: Routledge.

Masson, I., \& Österman, L. (2017). Working with female offenders in restorative justice frameworks:

Effective and ethical practice. The Probation Journal. Retrieved from http://journals. sagepub.com/doi/pdf/10.1177/0264550517728784

Maynard, M. (1994). Methods, practice and epistemology: The debate about feminism and research. In M. Maynard \& J. Purvis (Eds.), Researching women's lives from a feminist perspective (1st ed., pp. 10-26). London, England: Taylor \& Francis.

McIvor, G., Murray, C., \& Jamiesen, J. (2004). Desistance from crime: Is it different for women and girls. In S. Maruna \& R. Immarigeon (Eds.), After crime and punishment: Pathways to offender reintegration (1st ed., pp. 181-197). Cullompton, UK: Willan Publishing.

Miles, R. (2013). Restorative justice: Female offenders in restorative justice conferences.

London, England: The Griffin Society.

Miller, S. L. (2011). After the crime: The power of restorative justice dialogues between victims and violent offenders. New York: New York University Press.

Ministry of Justice. (2014). Update on delivery of the government's strategic objectives for female offenders. London, England: Ministry of Justice.

Moloney, K. P., van den Bergh, B. J., \& Moller, L. F. (2009). Women in prison: The central issues of gender characteristics and trauma history. Public Health, 123, 426-430.

Oakley, A. (1981). Interviewing women: A contradiction in terms. In H. Roberts (Ed.), Doing feminist research (1st ed., pp. 30-61). London, England: Routledge.

Offender Rehabilitation Act, c. 11. U.K. (2014).

Österman, L. (2018). Penal cultures and female desistance. London, England: Routledge.

Pope, C., Ziebland, S., \& Mays, N. (2000). Analysing qualitative data. British Medical Journals, 320, 114-116.

Rodriguez, N. (2005). Restorative justice, communities and delinquency: Whom do we reintegrate?

Criminology \& Public Policy, 4, 103-130.

Rumgay, J. (2004, June). When victims become offenders: In search of coherence in policy and practice. Paper presented at the Fawcett Society \& Nuffield Foundation Conference, London, England.

Scott, S., \& McManus, S. (2016). Hidden hurt: Violence, abuse and disadvantage in the lives of women (Executive summary). London, England: DMSS Research for AGENDA.

Shapland, J., Atkinson, A., Atkinson, H., Chapman, B., Dignan, J., Howes, M., Soresby, A. (2007). Restorative justice: The views of victims and offenders - The third report from the evaluation of three schemes (Ministry of Justice Research Series 03/07), National Offender Management Service 
Sherman, L. W., Strang, H., Mayo-Wilson, E., Woods, D., \& Ariel, B. (2015). Are restorative justice conferences effective in reducing repeat offending? Findings from a Campbell systematic review. Journal of Quantitative Criminology, 31, 1-24.

Strang, H. (2015, October 9). Research evidence for restorative justice: 10 things we know. Paper presented at the RJC event: Restorative Justice-A National Event for the Judiciary. London, UK.

Strang, H., Sherman, L. W., Mayo-Wilson, E., Woods, D., \& Ariel, B. (2013). Restorative justice conferencing (RJC) using face-to-face meetings of offenders and victims: Effects on offender recidivism and victim satisfaction. A systematic review. Campbell Systematic Reviews, Vol. 12.

Stubbs, J. (2002). Domestic violence and women's safety: Feminist challenges to restorative justice. In H. Strang \& J. Braithwaite (Eds.), Restorative justice and family violence (pp. 42-61). Cambridge, UK: Cambridge University Press.

Sutherland, J. A. (2010). Mothering, guilt and shame. Sociology Compass, 4, 310-321. Tyler, T. (2006). Restorative justice and procedural justice: Dealing with rule breaking. Journal of Social Issues, 62, 307-326.

Verrecchia, P. J. (2009). Female delinquents and restorative justice. Women and Criminal Justice, 19, 80-93.

Wood, W. R., \& Suzuki, M. (2016). Four challenges in the future of restorative justice. Victims $\mathcal{E}$ Offenders: An International Journal of Evidence-based Research, Policy, and Practice, $11,149-172$.

\section{Author Biographies}

Linnéa Österman is a lecturer in criminology at the University of Greenwich, London, United Kingdom. Her research interests revolve around gender and crime, desistance, qualitative comparative criminology, Nordic criminal justice, and restorative interventions.

Isla Masson is a lecturer in criminology at the University of Leicester, United Kingdom. Her research interests revolve around female offending, incarceration, restorative justice, rehabilitation, and offender management. 